\title{
Storage of Flowering Dogwood (Cornus florida L.) Pollen
}

\author{
J.H. Craddock ${ }^{1}$ \\ Tennessee State University Nursery Crop Research Station, 472 Cadillac \\ Lane, McMinnville, TN 37110
}

\section{S.M. Reed}

Floral and Nursery Plants Research Unit, U.S. National Arboretum, Agricultural Research Service, U.S. Department of Agriculture, 472 Cadillac Lane, McMinnville, TN 37110

\section{S.E. Schlarbaum}

Department of Forestry, Wildlife and Fisheries, The University of Tennessee, Knoxville, TN 37901-1071

\section{R.J. Sauve}

Cooperative Agricultural Research Program, Tennessee State University, 3500 John Merritt Blvd., Nashville, TN 37209

\section{Additional index words. in vitro pollen germination, cryopreservation}

\begin{abstract}
A series of experiments was conducted with flowering dogwood (Cornus florida L.) to evaluate in vitro pollen germination both prior to and following storage at various temperatures. For all experiments, pollen was germinated on an agar-solidified medium containing $20 \%$ sucrose. Collection method had a significant effect on germination of 'Cherokee Chief', 'Cherokee Princess', and 'Cloud 9' pollen. Pollen obtained from anthers that had been collected prior to dehiscence and allowed to air-dry for 24 hours had a higher germination rate than did pollen that had undergone a desiccation treatment. None of the treated pollen tested, however, had a germination rate $>25 \%$ of that of freshly collected pollen. The deleterious effect of dehydration could not be reversed by rehydration. Pollen germination was tested after $1,4,7$, and 108 days at $5,-20$, and $-196{ }^{\circ} \mathrm{C}$. Pollen stored at -196 and at $-20^{\circ} \mathrm{C}$ had a better germination rate than that stored at $5{ }^{\circ} \mathrm{C}$. Germination was not significantly affected by length of storage, nor was there any significant temperature $\times$ length of storage interaction.
\end{abstract}

Flowering dogwood is one of the most popular ornamental trees in the eastern United States. It is highly valued as a landscape tree because of its white, pink, or red bracts in the spring, autumn foliage color, and fruit display. Nurseries throughout the Southeast generate considerable revenues by producing and selling plants of this species; in Tennessee alone, flowering dogwood sales are estimated to be \$30-40 million annually (Southards, 1995). The aesthetic value of flowering dogwood is also important to the natural resource-based tourism industry of several states.

Recently, both nursery and native populations of flowering dogwood have been threatened by disease problems. Starting in the late 1970s, dogwood anthracnose, caused by

Received for publication 23 Feb. 1999. Accepted for publication 7 July 1999. This research was supported in part by U.S. Dept. of Agriculture Capacity Building Grant No. 92-38814-7490. The cost of publishing this paper was defrayed in part by the payment of page charges. Under postal regulations, this paper therefore must be hereby marked advertisement solely to indicate this fact.

${ }^{1}$ Current address: Dept. of Biological and Environmental Sciences, The Univ. of Tennessee at Chattanooga, 615 McCallie Ave., Chattanooga, TN 374032598. To whom reprint requests should be addressed. e-mail hill_craddock@utc.edu.
Discula destructiva Redlin, has resulted in widespread destruction of native stands of flowering dogwood in eastern forests (Sherald et al., 1996). Outbreaks of dogwood anthracnose in nurseries also have been reported. More recently, powdery mildew (Microsphaera pulchra C.\& P.) has emerged as a major problem on flowering dogwood. While not as destructive as dogwood anthracnose, powdery mildew can cause stunted, distorted growth that is undesirable aesthetically (Sinclair et al., 1987). Although fungicides are available for controlling anthracnose and powdery mildew on flowering dogwood, their use would result in an economic burden to growers. Application of these fungicides on large trees in a landscape setting is generally impractical.

Host plant resistance would be a desirable method of controlling both of these diseases. An anthracnose-resistant plant was found in the Catoctin Mountain Park, Md., and recently released as the cultivar Appalachian Spring (Windham et al., 1998). Resistance to powdery mildew has been reported in the cultivar Cherokee Brave (Hagan et al., 1998). In addition, a few plants selected from commercial seedling plots appear to have good resistance to powdery mildew (Windham and Witte, 1998).
Of the many cultivars of flowering dogwood available, most are phenotypic selections from natural or nursery populations and are propagated by budding. There are only a few published reports dealing with the breeding and genetics of this species (Orton, 1993). No information is available regarding the best way to collect, handle, and store flowering dogwood pollen. The purpose of this study was to develop a pollen storage system that would facilitate making crosses between plants that either flower at different times or are located some distance apart.

\section{Materials and Methods}

General procedures. Reed et al. (1996) reported that a medium containing $20 \%$ sucrose supported pollen germination in flowering dogwood, and this was used as the germination medium in this study. The sucrose was dissolved in distilled water, and $9 \mathrm{~g} \cdot \mathrm{L}^{-1}$ agar was added to solidify the medium. After autoclaving, $15-\mathrm{mL}$ aliquots of the medium were poured into 60 -mm-diameter plastic petri dishes.

Pollen was collected either from dehisced anthers on freshly opened flowers or from anthers that were collected prior to dehiscence. Freshly dehisced anthers were recognized by an abundance of fluffy pollen on their surfaces. This pollen was collected by holding flowers upside down over a petri dish and gently tapping them with a pair of forceps. Anthers collected prior to dehiscence were obtained from the largest unopened flowers on the inflorescence, placed on petri dishes, and allowed to dehisce at 21 to $22^{\circ} \mathrm{C}$. Field-grown plants were used for all experiments. Each pollen sample contained pollen collected from at least three individual plants per genotype.

A small brush was used to collect pollen in petri dishes. The pollen was distributed onto germination media by tapping the brush while holding it over the plate of media. The petri dishes were sealed and left at 21 to $22^{\circ} \mathrm{C}$ for 24 $\mathrm{h}$ and then examined under an inverted microscope. Pollen grains were examined on five areas of the petri dish, with a minimum of 100 grains scored per area examined. A pollen grain was scored as germinated if the pollen tube was at least as long as the diameter of the pollen grain. A mean percent germination was calculated for each sample using the germination rate of the five areas. Data were arcsin transformed when necessary to correct for heterogeneity of variance, and were subjected to analysis of variance. When the analysis of variance indicated a significant difference $(P$ $\leq 0.05$ ), means were separated by Fisher's least significant difference test.

Expt 1. The first experiment involved three pollen treatments and three genotypes ( 'Cherokee Princess', 'Cherokee Chief', and 'Cloud 9 '). For the control and one of the treatments, pollen was collected from anthers that had dehisced on the plant. Half of this pollen was immediately placed on germination media (control), while the other half was placed in a petri dish that was suspended over $\mathrm{CaSO}_{4}$ in a desiccator at room temperature (Treatment 
A). For the other two treatments, anthers that had not dehisced were collected and were either allowed to dehisce in open petri dishes (Treatment B) or over $\mathrm{CaSO}_{4}$ in a desiccator (Treatment C), both at 21 to $22^{\circ} \mathrm{C}$. After $24 \mathrm{~h}$, the pollen of all three treatments was collected and placed on germination media. The experiment was repeated for 5 consecutive days using one replicate dish per treatment per day. Differences in pollen germination of fresh pollen among flowering dogwood cultivars, and among pollen collected from the same cultivar on different days, had previously been observed by the authors (unpublished data). Therefore, all data were converted to a "percentage of control" value, which was equal to "100 $\times$ treatment \% germination/control \% germination." The germination of the fresh pollen of each cultivar on each day served as the control for all three treatments for that cultivar on that day. A two-way analysis of variance (ANOVA), using cultivar and treatment as main effects, was conducted.

Expt 2. 'Cherokee Chief' pollen was collected as in Expt. 1. Half of each pollen sample from all treatments and the freshly collected (control) pollen was placed on germination media in the manner indicated in Expt. 1, whereas the other half was rehydrated before placing it on germination medium. Rehydration consisted of placing pollen on a glass microscope slide and suspending the slide over water-saturated filter paper in a sealed petri dish at 21 to $22{ }^{\circ} \mathrm{C}$. The pollen was allowed to remain in this high-humidity atmosphere for $2 \mathrm{~h}$, then placed on germination medium. The experiment was repeated three times, on each of 3 consecutive days. A series of $t$ tests was performed to compare each rehydration treatment with the comparable non-rehydrated treatment.

Expt 3. Pollen was collected from freshly opened flowers of 'Cherokee Chief', 'Cherokee Princess', and a clone known as 'Rubra'. A sample of pollen was immediately placed on germination medium to serve as a control. The remaining pollen was divided and placed into 12 small cryogenic vials, and four vials of each were stored in a refrigerator $\left(5^{\circ} \mathrm{C}\right)$, a freezer $\left(-20{ }^{\circ} \mathrm{C}\right)$ or in liquid nitrogen $\left(-196{ }^{\circ} \mathrm{C}\right)$. Samples were plated on germination medium after 1, 3, 7, and $108 \mathrm{~d}$ of storage. A "percentage of control" value was calculated for each sample as in Expt. 1, with the mean germination of the fresh pollen of each cultivar serving as the control for all samples of that cultivar. The experiment was repeated three times. Data were combined over cultivars, and a two-way ANOVA, using storage temperature and time of storage as main effects, was conducted.

\section{Results and Discussion}

Expt 1. Pollen germination, expressed as a percentage of the germination of freshly collected pollen, was not significantly affected by either cultivar or cultivar $\times$ treatment interaction, whereas storage treatment had a highly

Table 1. Effect of rehydration on germination in vitro of 'Cherokee Chief' flowering dogwood pollen subjected to different collection and drying treatments. All treatments performed at 21 to $22^{\circ} \mathrm{C}$.

\begin{tabular}{lccc}
\hline \hline & \multicolumn{2}{c}{$\begin{array}{c}\text { Pollen germination } \\
\text { Mean (range) }\end{array}$} \\
\cline { 2 - 3 } Treatment & \multicolumn{2}{c}{ Ron-rehydrated } & \multicolumn{2}{c}{ Rehydrated } & LSD $_{0.05}$ \\
\hline $\begin{array}{l}\text { Freshly collected } \\
\begin{array}{l}\text { Collected from freshly dehisced anthers; } \\
\text { desiccated 24 h }\end{array}\end{array}$ & $3.7(50 \%$ to $70 \%)$ & $60.3(42 \%$ to $73 \%)$ & 31.5 \\
$\begin{array}{l}\text { Nondehisced anthers collected, } \\
\text { pollen obtained after 24 h }\end{array}$ & $6.0(3 \%$ to $6 \%)$ & $36.3(2 \%$ to $60 \%)$ & 49.0 \\
$\begin{array}{l}\text { Nondehisced anthers collected, } \\
\text { pollen obtained after 24 h over desiccant }\end{array}$ & $17.0(11 \%$ to $23 \%)$ & 11.2 \\
\hline
\end{tabular}

significant effect. Pollen that was stored over a desiccant (Treatments $\mathrm{A}$ and $\mathrm{C}$ ) had a significantly lower germination rate $(11.1 \%$ and $9.1 \%$ of control, respectively) than did pollen that was obtained from anthers that were collected before dehiscence and allowed to remain in open air for $24 \mathrm{~h}(24.6 \%)$. The reduction in germination following desiccation was not related to temperature of storage, as similar results were found when desiccation was carried out in a refrigerator (Reed et al., 1996).

Expt 2. Rehydration reportedly improves in vitro germination of desiccated pollen of some species (Polito and Luza, 1988; Yates and Sparks, 1989). In contrast, rehydration of desiccated flowering dogwood pollen did not affect germination percentages significantly (Table 1). However, considerable variation between replications was observed in the rehydrated treatments. Data for germination of freshly collected pollen, with and without rehydration, indicated that rehydration was not detrimental to germination. Additional experiments, utilizing different dehydration and rehydration protocols, are needed to more fully elucidate the effect of rehydration on germination of desiccated flowering dogwood pollen.

Expt 3. Pollen germination was not significantly affected by length of storage, nor was there any significant temperature $\times$ length of storage interaction. Such effects might have been observed, however, if longer storage periods had been tested. Storage temperature had a highly significant effect. Pollen stored at $-196{ }^{\circ} \mathrm{C}\left(59.5 \%\right.$ of control) and at $-20{ }^{\circ} \mathrm{C}$ $(52.5 \%)$ germinated significantly better than that stored at $5{ }^{\circ} \mathrm{C}(27.0 \%)$. Increased microbial activity that might be expected at the warmer storage temperature, especially in nondesiccated conditions, may have reduced viability during storage at $5^{\circ} \mathrm{C}$.

Based on the results of the tests conducted in this study, the best protocol for preservation of flowering dogwood pollen appears to be collecting freshly dehisced anthers and storing the pollen, without desiccation, in either a freezer $\left(-20^{\circ} \mathrm{C}\right)$ or in liquid nitrogen $(-196$ ${ }^{\circ} \mathrm{C}$ ). Even under these storage conditions, however, pollen germination fell to $50 \%$ to $60 \%$ of that of freshly collected pollen. Therefore, the use of freshly gathered pollen for flowering dogwood pollinations is recommended, where practical. Note that in all three experiments in this study, in vitro pollen germination was used as the sole indicator of pollen viability. The most reliable test of the effect of a storage treatment is to determine if the pollen still functions in fertilization. While no empirical data is available to demonstrate the effectiveness of stored flowering dogwood pollen in effecting fertilization, limited numbers of controlled pollinations have been made with 'Cherokee Brave' and 'Cherokee Chief' pollen following storage, without desiccation, in liquid nitrogen for 1 month. These pollinations were successful in producing seed, but additional experimentation is necessary before conclusions can be drawn as to effectiveness of this storage protocol for flowering dogwood.

\section{Literature Cited}

Hagan, A.K., B. Hardin, C.H. Gilliam, G.J. Keever, J.D. Williams, and J. Eakes. 1998. Susceptibility of cultivars of several dogwood taxa to powdery mildew and spot anthracnose. J. Environ. Hort. 16:147-151.

Orton, E.R., Jr. 1993. New large-bracted dogwoods from Rutgers University. Proc. Intl. Plant Prop. Soc. 43:487-490.

Polito, V.S. and J.G. Luza. 1988. Longevity of pistachio pollen determined by in vitro germination. J. Amer. Soc. Hort. Sci. 113:214-217.

Reed, S.M., J.H. Craddock, S. Schlarbaum, and R. Sauve. 1996. Storage of dogwood (Cornus florida) pollen. Proc. Southern Nurserymen's Assn. Res. Conf. 41:355-358.

Sherald, J.L., T.M. Stidham, J.M. Hadidian, and J.E. Hoeldtke. 1996. Progression of the dogwood anthracnose epidemic and the status of flowering dogwood in Catoctin Mountain Park. Plant Dis. 80:310-312.

Sinclair, W.A., H.H. Lyon, and W.T. Johnson. 1987. Diseases of trees and shrubs. Comstock, Ithaca, N.Y.

Southards, C.J. 1995. Battling dogwood anthracnose. Tennessee AgriScience 175:7-10.

Windham, M.T. and W.T. Witte. 1998. Naturally occurring resistance to powdery mildew in seedlings of Cornusflorida. J. Environ. Hort. 16:173175 .

Windham, M.T., E.T. Graham, W.T. Witte, J.L.Knighten, and R.N. Trigiano. 1998. Cornus florida 'Appalachian Spring': a white flowering dogwood resistant to dogwood anthracnose. HortScience 33:1265-1267.

Yates, I.E. and D. Sparks. 1989. Hydration and temperature influence in vitro germination of pecan pollen. J. Amer. Soc. Hort. Sci. 114:599-605. 